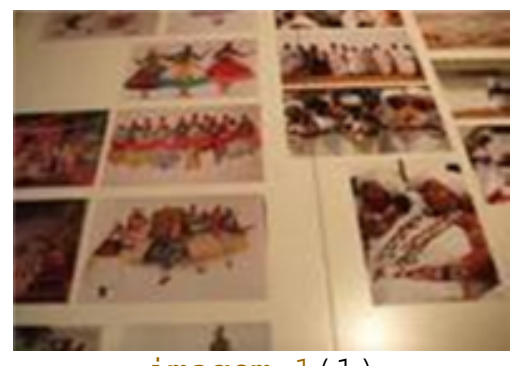

imagem $1(1)$

\title{
Documenta 12
}

\section{Günther Augustin}

Prof. de Literatura Comparada e Cultura Alemã. Faculdade de Letras/UFMG.

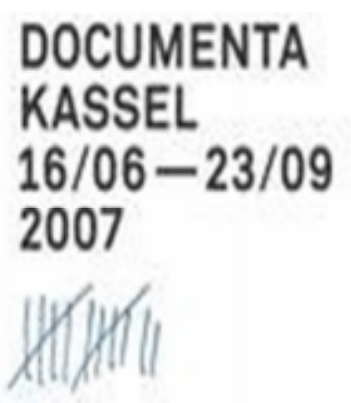

imagem $2(2)$
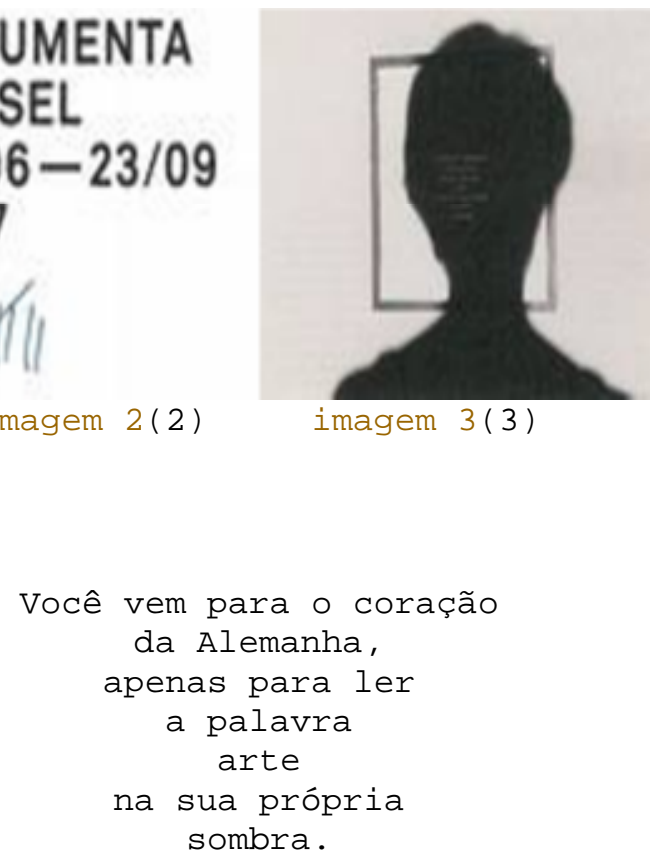

Essa frase, escrita na sombra da cabeça do espectador, é emblemática para a forma e o conteúdo da Documenta 12, o museu por 100 dias, a mais importante mostra mundial de arte contemporânea, a mostra do vanguardismo. Pela décima segunda vez, a documenta abriu suas portas para artistas e peritos, flâneurs e curiosos. O mundo das artes veio, de 16/06 até 23/09 de 2007, para a terra dos irmãos Grimm.

$\mathrm{Na}$ edição de 2007, encontramos, ao lado de quadros de pintura e escultura tradicionais, muitas assim chamadas instalations, sejam de objetos concretos, fotografias, slides, vídeos ou 
jogos de luzes. E muita presença de texto nas telas. Como na instalação Eclipsis do chileno Gonzalo Díaz, onde encontramos a frase acima citada. O artista convida o visitante a uma participação individual na sua montagem visual. No interior da sala Beuys, uma fonte de luz projeta um circulo luminoso na parede do outro lado da sala. Nesse círculo, encontra-se uma moldura, formando um quadro à primeira vista vazio. Quando o espectador é convidado a aproximar-se dessa moldura, ele interrompe o raio de luz projetando uma sombra no quadro, no centro do qual agora aparece a frase acima citada, em alemão (4). O corpo do espectador é o elemento chave para fazer o antes invisível visível. A rigor, ver e ler são processos heterogêneos que não operam simultaneamente. Onde a gente vê, a gente não lê, e vice versa. Mas na camera lucida da instalação Eclipsis a intervenção do corpo do indivíduo, a projeção da sua sombra permite para um momento a simultaneidade das duas atividades. O ver é resgatado pelo ler; e a arte precisa do ver.(5)

Foi minha terceira ou quarta vez que visitei aDocumenta 12, que ocorre a cada cinco anos, desde 1955. Lembro como nos anos sessenta pintores como Andy Warhol ou Roy Lichtenstein representavam a vanguarda, e como Joseph Beuys me deu uma das suas sacolas plásticas onde desenhou, num lado, o modelo da democracia representativa, e no outro, um da democracia direta. Hoje são clássicos do século xx. Documentar esse processo de transformação de sementes de vanguardas em padrão estético sempre foi a proposta ambiciosa da documenta. E não é por acaso que uma das temáticas dessadocumenta foi a modernidade, e que o segundo artigo do seu magazine é um texto sobre a questão "Is Modernity our Antiquity?", retomando e questionando as reflexões baudelairianas em Le peintre de la vie moderne. (6)

Como mostrar esse processo? Lembrando as origens da documenta, - organizador daDocumenta 12 procura explicar as intenções ambiciosas dos fundadores dessa mostra. A primeira foi organizada nos escombros de um país destruído pelo regime nazista e seu furor aniquilador. Escolheram a ruína de um castelo representativo do iluminismo do século XVIII, construído pouco antes da Revolução Francesa e destruído pelas bombas da 2a. Guerra Mundial. Nessas ruínas emblemáticas do esclarecimento em ruínas, os organizadores procuraram reconciliar o público alemão com a tradição moderna, brutalmente interrompida pela ditadura nazista. Procuraram mostrar as raízes da arte moderna, a genealogia da arte atual, seu posicionamento atual, mostrando pela arte as rupturas da modernidade e sua experiência fundamental: a da contingência dos acontecimentos, a ausência da linearidade histórica. Optaram pelo artifício da "encenação" na medida que as obras não foram fixadas nas paredes, mas colocadas no espaço dos 
ambientes da ruína provisoriamente transformada em uma espécie de oficina de visualização, possibilitando ao mesmo tempo maior contato e distanciamento, criando uma maior interação do espectador com a obra. Nesse ambiente, o espectador e a obra, - sujeito e o objeto participaram de um mundo comum. Frente à obra, o próprio espectador virou objeto até que essa divisão começou a desfazer-se. O mesmo vale para a obra de arte vanguardista. Ela ainda não é objeto fixável, não é identificável, ainda parece fora do tempo histórico. Ainda não há nada para "entender". O visível fornece "apenas" uma experiência sensível, sem pré-conceituação, sem identidade. E - ambiente no seu conjunto de arquitetura, obras e público torna-se um espaço público de reflexão sobre possíveis sentidos e identidades(7). Reflexões estéticas e sócioculturais, que a documenta sempre soube integrar, ou nunca quis desvincular.

Essa marca do não-idêntico, do novo ainda de difícil classificação ou conceituação, mas atual e contemporâneo, manteve-se durante o meio século de mostras da documenta. Tanto que os organizadores da $12^{a}$ edição fizeram questão de frisar que os critérios de escolha dos artistas e suas obras não foram épocas ou estilos ou tendências, nem artistas ou países. É verdade que tinha que ter critérios e que eles ficaram um tanto nebulosos. Pelo menos não consegui identificá-los nem durante a mostra nem na documentação oficial. O que me tranqüilizou um pouco foram as afirmações de que essa mostra não deveria ser uma extensão do mercado de arte. O meu critério de escolha para esse depoimento contradiz um pouco essa filosofia, porque não podia deixar de registrar a presença brasileira na Documenta 12, e dentro dela a representação de tópicos do nosso trabalho na FALE/UFMG. Assim, duas instalationschamaram a minha atenção: a da dupla Mauricio Dias, brasileiro, e Walter Riedweg, suíço, e outra do nigeriano David Aradeon.

Em sua Media Installation "Funk Staden" Dias \& Riedweg transferem para a cultura funk nas favelas de Rio de Janeiro, a história de Hans Staden, autor do primeiro relato sobre o Brasil em alemão, publicado em 1557 e muito difundido na Europa. Vale lembrar que o relato de Staden contribuiu na formação do mito dos trópicos selvagens e canibalísticos que estimulou a imaginação européia e ajudou a legitimar a violência colonial. A história de staden como instalação de vídeo relaciona a costa brasileira de 1557 com sua realidade de 450 anos mais tarde. Agora os antropófagos são os marginais urbanos. Os funkeiros devoram a tecnologia e a utilizam para seu canto de guerra. Durante um churrasco na favela, os funkeiros encenam nove das gravuras ilustrativas do livro de Staden que apareçam no vídeo intercaladas entre as encenações. 
Com isso, Dias \& Riedweg procuram destacar e questionar os estereótipos criados pelos relatos dos viajantes:

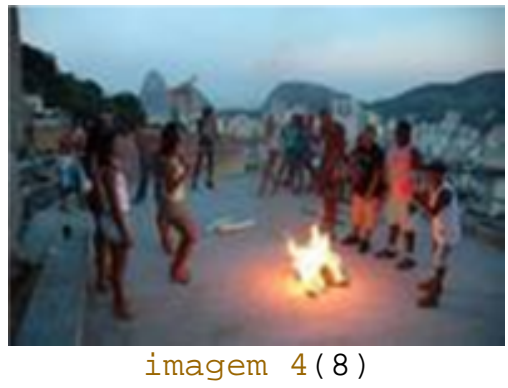

The contemporary anthropophagist is the marginalized urban dweller: junkers devour electronic technology, making of it the means of communication for their ancestral chant. The dance-eye of the Ibirapema-camera conducts the narrative, cutting through the layers of stereotypes that separate us from this other and masks the violence of this relationship. (9)

$\mathrm{Na}$ sua installation "Movement of Forms. Antecedents of AfroBrazilian Spaces", David Aradeon, arquiteto e urbanista nigeriano, tematiza com sua instalação fotográfica a interação cultural afro-brasileira. "From language to fashion, Candomble to Carneval, Samba music to Samba the dance, the Bantu speaking groups from the old Ki-Congo kingdom and the Fon and Nago-Yoruba group from Nigeria/Benin had an indelible influence on Brazilian culture."(10) Suas fotografias mostram a presença das deusas Oshun e Yemoja e do deus Chango na afroamérica. "From Cuba to Trinidad including Brazil, Sango, Xango, Chango, the Yoruba God of Thunder, Lighning and Justice is the principal god mentioned in songs."(11)

Além da herança africana no Brasil, Aradeon documenta com suas fotografias a circulação das influências, na medida em que mostra traços da arquitetura afro-brasileira de volta no Oeste da África: "In the costal cities of West Africa the remarkable recreation of the linear details and ornamentation on the architecture of the Mosques and houses attest to the remarkable power of creative interpretation and inventive adaptations by generations of locally trained artisans." (12)

Uma novidade dessa Documenta 12 foi o DOCUMENTA MAGAZINE onde as reflexões sobre a arte contemporânea e sua inserção no contexto sócio-cultural foram documentadas. Seus textos e imagens são resultado de um processo de reflexão, discussão, polêmicas e traduções culturais em rede virtual e global. Um ano e meio antes do início da Documenta 12, os organizadores convidaram quase cem publicações dos mais diversos formatos e tendências do mundo da arte, cultura e teoria, de pequenos grupos de artistas, jornais, revistas, periódicos acadêmicos até publicações on-line, para refletirem sobre os leitmotive e 
temáticas da Documenta 12, dentre eles, três revistas eletrônicas brasileiras: Canal contemporâneo,

Rizoma.net e Trópico. As contribuições foram agrupadas em três capítulos com os títulos "Modernity", "Life" e "Education".

The editorial groups invited to participate can be compared with small academies. They are educational and transmission stations between those who make art and those who think about it ... Their efforts activate and make available material which goes beyond that repeated to the point of banality in the mainstream world. Among our partners hardly any magazines work in the direction of the strong forces of the market and lifestyle industries. (13)

Essa linha editorial encontra-se em sintonia com a mostra visual. Ambos agradaram pela abordagem intercultural e pelo vanguardismo na medida que procur(ar)am estabelecer uma rede de criatividade e reflexão global sem sucumbir às pressões do mercado globalizado.

\section{Notas}

[1] ARADEON, 2007. p. 212.

[2]capa: Documenta und Museum Fridericianum Veranstaltungs-Gmbh, Kassel

(Hrsg. | Editor). documenta 12 Katalog | Catalogue. Köln: Taschen GmbH, 2007 .

[3]DIAS, 2007.p. 235. Foto Egbert.

[4]Du kommst zum Herzen Deutschlands, nur um das Wort

Kunst

unter deinem eigenen

Schatten

[5] OYARZUN, 2007.p. 234.

[6] LEWIS, 2007 . p. 41.

[7] BUERGEL, 2007. p. 25-38.

[8] ROLNIK, 2007.p. 232.

[9]DIAS E RIEDWEG, 2007.p. 233.

[10] ARADEON, 2007. p. 212. 
[11] ARADEON, 2007 . p. 212 .

[12] ARADEON, 2007 . p. 212 .

[13] Documenta und ... 2007b, p. 5 .

\section{Bibliografia}

ARADEON, D. DAVID ARADEON Movement of Forms. Antecedents of Afro-Brazilian Spaces Installation. In: Documenta und Museum Fridericianum VeranstaltungsGmbh, Kassel (Hrsg. | Editor). Documenta 12 Katalog | Catalogue. Köln: Taschen GmbH, 2007, p. 212 .

BUERGEL, R. M. Der Ursprung. In: Documenta und Museum Fridericianum Veranstaltungs-Gmbh, Kassel (Hrsg. | Editor).DOCUMENTA MAGAZINE NO 1-3, 2007 READER. Köln: Taschen GmbH, 2007b, p. 25-38. Documenta und Museum Fridericianum Veranstaltungs-Gmbh, Kassel (Hrsg. Editor). Documenta 12 Katalog | Catalogue. Köln: Taschen GmbH, 2007.

Documenta und Museum Fridericianum Veranstaltungs-Gmbh, Kassel (Hrsg. Editor). Documenta Magazine n. 1-3, 2007. READER. Köln: Taschen GmbH, 2007b. http://magazines.documenta.de/frontend/index.php?IdMagazine=139 (acessado em $16 / 09 / 07)$

http://www.canalcontemporaneo.art.br/quebra/archives/001359.html (acessado em $16 / 09 / 07$ )

http://www.documenta12.de/ (acessado em 16/09/07)

http://www.galeriavermelho.com.br/v2/artistas.asp?idioma=pt\&estaPagina=text os\&id_artistas=30 (acessado em 16/09/07)

LEWIS, M. Is Modernity our Antiquity? In: . Documenta und Museum Fridericianum Veranstaltungs-Gmbh, Kassel (Hrsg. Editor).Documenta Magazine n. 1-3, 2007 READER. Köln: Taschen GmbH, 2007b, p. 40-65.

OYARZUN, P. 2007 Gonzalo Díaz Eclipsis, Installation. In: Documenta und Museum Fridericianum Veranstaltungs-Gmbh, Kassel (Hrsg. | Editor). Documenta 12 Katalog | Catalogue. Köln: Taschen GmbH, 2007, p. 234.

ROLNIK, S. 2007 DIAS \& RIEDWEG Funk Staden Medieninstallation. In: Documenta und Museum Fridericianum Veranstaltungs-Gmbh, Kassel (Hrsg. Editor). Documenta 12 Katalog | Catalogue. Köln: Taschen GmbH, 2007, p. 232.

\section{Agradecimento}

A visita à Documenta 12 contou com recursos do Fundo de Apoio Acadêmico da FALE/UFMG. 